\title{
Os jesuítas e o patrimônio cultural material: o caso dos bens tombados no Espírito Santo
}

\author{
The jesuits and the material cultural heritage: the case of the \\ registered properties in the Espirito Santo
}

\section{SANDRA C. A. PELEGRINI ${ }^{1}$ JACQUELINE RODRIGUES ANTONIO ${ }^{2}$}

\begin{abstract}
1 Doutora em História Social pela Universidade de São Paulo (USP), Estágio pós-doutoral em Patrimônio Cultural pela Universidade de Campinas (UNICAMP), docente da Universidade Estadual de Maringá, coordenadora do Centro de Estudos das Artes e do Patrimônio Cultural (CEAPAC/UM) e do Museu da Bacia do Paraná

(MBP/UEM). E-mail: sandrapelegrini@yahoo.com.br

2 Mestre pelo Programa de Pós-Graduação em História, da Universidade Estadual de Maringá, linha de pesquisa "Fronteiras, populações e bens culturais", bolsista da Capes. E-mail: lili240386@yahoo.com.br
\end{abstract}

\begin{abstract}
Os jesuítas construíram diversos edifícios que abrigaram templos religiosos, escolas e suas residências no decorrer do período colonial na América Portuguesa. Muitos deles foram erguidos na capitania do Espírito Santo, como, por exemplo, a Igreja e Residência dos Reis Magos (Nova Almeida) e a Igreja Nossa Senhora da Assunção (Anchieta). Tais edifícios, assim como seu acervo, foram conservados pela população local e sendo tombados no ano de 1943, mediante a implementação das políticas de preservação dos bens materiais, favorecidos pela criação do Serviço de Patrimônio Histórico e Artístico Nacional, atualmente conhecido como Instituto do Patrimônio Histórico e Artístico Nacional . Dessa forma, este texto tem por objetivo demonstrar como os jesuítas promoveram a conservação do patrimônio cultural material em Nova Almeida e Anchieta, respectivamente na década de 1980 e nos anos finais do século XX.
\end{abstract}

Palavras-chave: Iphan, história cultural, bens materiais.

The Jesuits erected several buildings that housed religious temples, schools, and their residences during the colonial period in Portuguese America. Many of them were built in the Espírito Santo captaincy, for example, the Igreja e Residência dos Reis Magos [Church and Residence of the Magi] (Nova Almeida) and the Igreja Nossa Senhora da Assunção [Church of Our Lady of Assumption] (Anchieta). These buildings, as well as their collection, were preserved by the local population and were listed as a protected historic landmark in 1943, through the implementation of policies for the preservation of material assets, favored by the creation of the National Historical and Artistic Heritage Service, now known as the National Institute of Historical and Artistic Heritage. The purpose of this text is to demonstrate how the Jesuits promoted the conservation of the material cultural heritage in Nova Almeida and Anchieta, carried out in the 1980 s and in the final years of the 20th century, respectively.

Keywords: Iphan, cultural history, material assets. 


\section{INTRODUÇÃO}

Ao ler os dois livros produzidos após uma intervenção a fim de conservar os bens tombados de Nova Almeida e Anchieta, é perceptivo que, por trás desses bens materiais, há uma história que revela a atuação dos jesuítas no Brasil, a conservação dos edifícios no passar dos anos e a política que levou à salvaguarda destes patrimônios.

Em 1936 Mário de Andrade formula um anteprojeto para a salvaguarda do patrimônio brasileiro. Um dos expoentes do movimento modernista e defensor da tutela do patrimônio cultural brasileiro, o poeta foi convidado pelo então ministro da Educação e Saúde, Gustavo Capanema, para elaborar tal anteprojeto que serve como base para o futuro Serviço de Patrimônio Histórico e Artístico Nacional (SPHAN), o atual Instituto do Patrimônio Histórico e Artístico Nacional (Iphan). Dessa forma, o Decreto-Lei n ${ }^{\circ} 25$, de 30 de novembro de 1937, que cria o Iphan, foi concebido a partir do anteprojeto de Mário de Andrade, com algumas modificações, como a retirada de qualquer proteção ao patrimônio imaterial, focando, assim, na questão material da cultura brasileira.

Nesse período que estava definindo quais patrimônios são dignos de ser preservados dentro da política da identidade brasileira, houve uma preferência, a princípio, para aqueles da "era primitiva" brasileira, entendida como a era colonial. Assim, é nesse contexto que os monumentos e acervo dos jesuítas, esquecidos desde 1759, tornam-se o centro das atenções na questão da salvaguarda do patrimônio cultural.

Das diversas construções feitas pelos jesuítas, raras foram preservadas em sua função no período colonial e foram tombadas pelo Iphan nos anos de 1930 e 1940. Algumas foram modificadas para sua nova funcionalidade, outras restaram, mas apenas poucas de suas estruturas. Um bom exemplo de patrimônio que foi totalmente adaptado para novos papéis após a expulsão dos jesuítas é o Palácio Anchieta, que atualmente abriga o gabinete do governador do Espírito Santo e guarda poucos resquícios da época jesuítica.

Há também aqueles que restaram ruínas, como o caso do Convento São Francisco, ao lado da Cúria Metropolitana de Vitória. Porém, no estado do Espírito Santo há dois exemplos de construções jesuítas que foram preservadas pela população local com atribuições originalmente designadas, e após o tombamento de ambas em 1943, foram restauradas o mais próximo a como eram até o século XVIII, segundo os estudos arqueológicos realizados, e pelas estruturas aparentes.

A primeira é a Igreja e Residência dos Reis Magos, concluída em 1580 na antiga Aldeia dos Reis Magos que, após a expulsão dos jesuítas, fruto das reformas pombalinas de 1759 da qual previa uma ocultação da memória jesuítica, passou a ser nomeada como Nova Almeida em homenagem a Almeida em Portugal; a segunda, a Igreja Nossa Senhora da Assunção, teve sua construção iniciada em 1579 na antiga Aldeia de Reritiba que, pelos mesmos motivos de Nova Almeida, teve seu nome alterado para Vila Nova de Benevente e em 1887 passou a ser conhecida como Anchieta por ter sido a última morada do padre.

Com o reconhecimento dos dois patrimônios como bens materiais a serem protegidos pelo Estado, dentro do Decreto-Lei 25/1937 há a prerrogativa da conservação ou reparação pelo Iphan dos bens tombados. Logo, nesses mais de 70 anos de preservação pelo Estado, foram realizadas algumas obras de restauração, tanto do edifício como dos bens móveis.

As restaurações resultaram em produções que, além de ressaltar alguns aspectos marcantes dessas obras, também serviram como uma espécie de "prestação de contas" acerca de sua salvaguarda para a sociedade.

O Caderno de restauração 1: Retábulo e elementos de cantaria da Igreja do convento dos Reis Magos Nova Almeida - Espirito Santo faz parte de uma coleção lançada pela empresa Restauro para a divulgação das obras por ela restauradas desde 1987. No primeiro volume, foram enfatizados os estudos realizados para restauração do Retábulo e dos elementos de cantaria da Igreja e Residência dos Reis Magos.

Por sua vez, o livro Anchieta: a restauração de um santuário foi feito pela 6 a Coordenação Regional do Iphan em conjunto com o Ministério da Cultura com o objetivo de divulgar à comunidade os trabalhos obtidos na restauração da Igreja de Nossa Senhora da Assunção.

Dessa forma, a partir das duas produções, de dois patrimônios materiais dos jesuítas tombados no Espírito Santo, salvaguardados pelo Iphan, com o paradigma indiciário, proposto por Carlo Ginzburg (1989), do qual, pelos os detalhes na cultura material, vemos a herança jesuítica, assim como a política para sua preservação e as medidas tomadas para tal. 


\section{Os JESUÍTAS E A CULTURA MATERIAL DEIXADA NO EsPÍRITO SANTO}

Percorrendo o estado do Espírito Santo, encontram-se diversas obras realizadas pelos jesuítas durante a sua estadia no período colonial do Brasil. De alguns edifícios sobraram as ruínas, outros foram totalmente modificados, porém houve aqueles que sobreviveram à ação do tempo e da política vigente. Para compreender a importância da cultura material deixada pelos jesuítas no estado, é necessário que se recorra ao valor da atuação jesuíta na então América portuguesa, e também o que motivou esse retorno colonial na política de preservação patrimonial.

Ambos os livros evidenciam a importância jesuítica para o estado do Espírito Santo, ressaltando a questão da missionação, da qual teve como evidências a cultura material deixada por eles desde a colonização até às políticas pombalinas para a expulsão dos jesuítas em 1759 .

Depois da década de 1730, o "projeto de colonização associou-se, então, o projeto de catequese das populações indígenas" (ALMEIDA, 2014, p. 437). Dessa forma, a dificuldade de escravizar os índios, somada à Reforma Religiosa na Europa, acarretou uma aliança entre a Coroa e a Igreja no envio de religiosos do clero regular, em especial, da recém-formada Companhia de Jesus, para a América portuguesa, a qual a Coroa controlava em todos os âmbitos exceto nos assuntos acerca da doutrina e dos dogmas que a Igreja ainda cuidava.

Foi na política de aldeamento das Coroas Ibéricas que a ideia de peregrinação missionária realizadas na África e na Ásia foi substituída pela de fixação de missionários na América portuguesa. Nesse contexto há construção de igrejas, residências e colégios pelos jesuítas, assim como a produção ou importação de bens móveis religiosos, como pinturas, estátuas, retábulos e objetos litúrgicos, tornando estes o princípio de uma cultura branca europeia em terras tupiniquins.

Na primeira metade do século XX, no período em que Getúlio Vargas estava no governo, houve diversas leis criadas a fim de preservar os patrimônios histórico-culturais do Brasil. Destaca-se dois anos, de 1934, em que a proteção se dava por meio da Constituição impedindo a evasão de obras de arte do Brasil, e o ano de 1937, do qual se evidencia três eventos: a Carta Magna que favorece a instauração da Lei do Tombamento; o Decreto-Lei 25/1937 que coloca a propriedade privada ao interesse do coletivo (ingerência do Estado); e o SPHAN sendo cunhado e inaugurando suas atividades.

Dentro dessa política há dois grupos disputando quais bens materiais eram dignos de salvaguardo: os modernistas, que defendiam um lado político e histórico; e os neocoloniais, de caráter estético, tendo por objetivo "um retorno às formas de um Brasil colonial" (CAVALCANTI, 2006, p. 30). A princípio, no universo político vigente que buscava por meio do tombamento uma construção da identidade nacional com base na unidade do país, a preservação dos bens materiais do período colonial seria um passado em comum a todos, e assim, representaria genuinamente o Brasil, definindo o "ser brasileiro". Após esse período inicial, a proposta que prevalece é a modernista.

Ainda na fase inicial do projeto dos tombamentos da cultura material do País, houve no ano de 1943 o registro de dois importantes monumentos jesuíticos presentes no estado do Espírito Santo, por se manterem o mais próximo ao que era no período colonial: a Igreja e Residência dos Reis Magos e a Igreja Nossa Senhora da Assunção, ambas no dia 21 de setembro. Com esses edificios foram tombados os bens móveis que estavam em seu interior, sejam pinturas, estátuas e outros. Assim, a memória da cultura material deixada pelos jesuítas no Espírito Santo é ressaltada, depois de anos tentando apagá-la.

\section{O Estudo E A RESTAURAÇÃo EM Nova Almeida}

Em 1943, quando foi tombado o monumento arquitetônico dos Reis Magos em Nova Almeida, os bens materiais imóveis também o foram, como os elementos de cantaria e o retábulo (FIGURA 1). No fim dos anos de 1940 e início dos anos de 1950, foi feita a primeira restauração nesse conjunto jesuítico. Na década de 1980 foi feita outra restauração, tendo como resultado, além da conservação desses elementos citados, um livro para evidenciar o processo desse restauro, o Caderno de restauração 1: Retábulo e elementos de cantaria da Igreja do convento dos Reis Magos Nova Almeida - Espírito Santo.

Visualizando os rastros deixados pelo monumento e evidenciados pelo livro, primeiro nota-se, com o breve histórico do edifício posto, que é destacada a atuação dos jesuítas e a construção do aldeamento dos Reis Magos e da igreja. 
Figura 1. Desenho do retábulo da Igreja dos Reis Magos, Nova Almeida, Espírito Santo.

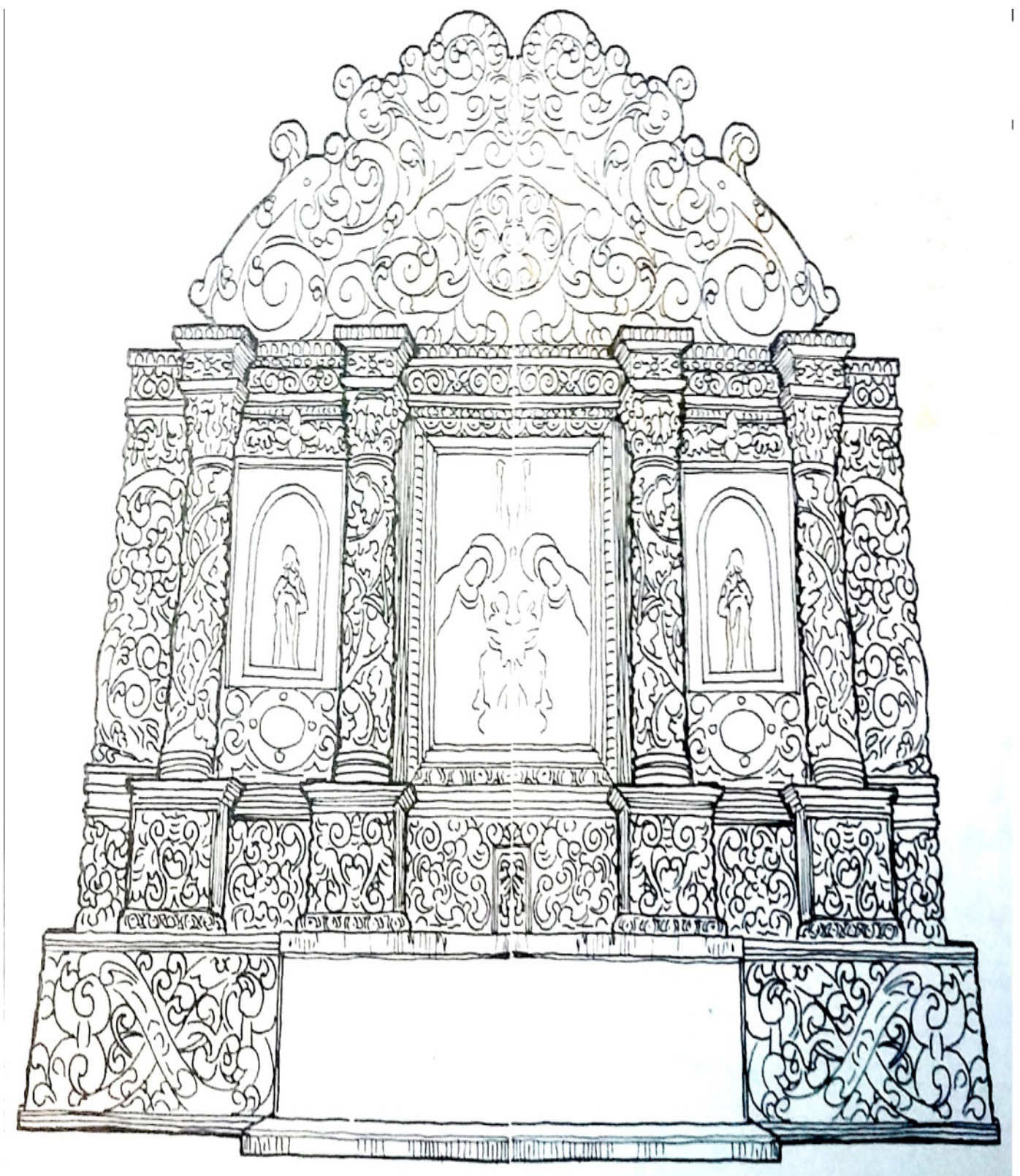

Fonte: Motta; Ramos, 1990, p. 14.

Posteriormente é evidenciada a história da evolução estilística, colocando o retábulo localizado no altar-mor como fazendo parte disso, como vemos na imagem posta pelos autores, tendo a preocupação de deixar o retábulo da maneira que Edson Motta projetou na primeira intervenção do Iphan, e não como se acredita que era no período colonial.

Após o histórico destaca-se a importância do retábulo da Igreja dos Reis Magos, colocando como "uma das principais esculturas de interesse artístico-histórico do Espírito Santo" (MOTTA; RAMOS, 1990, p. 15), como um tardio protobarroco, levantando a hipótese que os jesuítas orientaram os indígenas na execução dessa obra. Sobre o painel dos Reis Magos no centro do retábulo, é exposto que tanto poderia ter sido encomendada da Europa como pintada por um jesuíta. Diante disso discorre-se sobre como ocorreu a conservação desde que o SPHAN assumiu esse papel, dando destaque para os feitos da equipe da Universidade Federal do Espírito Santo. 
Com a importância do retábulo e de sua conservação explícitos, os autores se dedicam a conceitualizar a restauração de forma a justificar todas as intervenções feitas nesse bem material, ao expor que "restaurar uma obra de arte objetiva repô-la em condições físicas e estéticas aceitáveis" (MOTTA; RAMOS, 1990, p. 17). Após essa explicação é relatado como o retábulo foi tratado, bem como o mapeamento e a montagem da obra; os elementos de cantaria foram reparados e limpos; em relação às portas e janelas, foi feita uma intervenção para prevenir danos dos sais marinhos, uma vez que o monumento se localiza no litoral espírito-santense.

Portanto, esse livro, além de ressaltar a importância histórica desse bem tombado, também traz à luz as ações preservacionistas do Iphan para a sua conservação.

\section{O ESTUdO E A RESTAURAÇÃO EM ANCHIETA}

O livro Anchieta: a restauração de um santuário foi uma iniciativa do Iphan/ES a fim de relatar os trabalhos da restauração da Igreja Nossa Senhora da Assunção (FIGURA 2), como forma de difundir e estimular o interesse pelo monumento. Com a Igreja e Residência dos Reis Magos esse edifício foi tombado, porém, ao contrário da Igreja dos Reis Magos que continua sendo paróquia, com uma parte dedicada a um museu, a Igreja Nossa Senhora da Assunção é somente museu.

Figura 2. Igreja Nossa Senhora da Assunção, Anchieta, Espírito Santo.

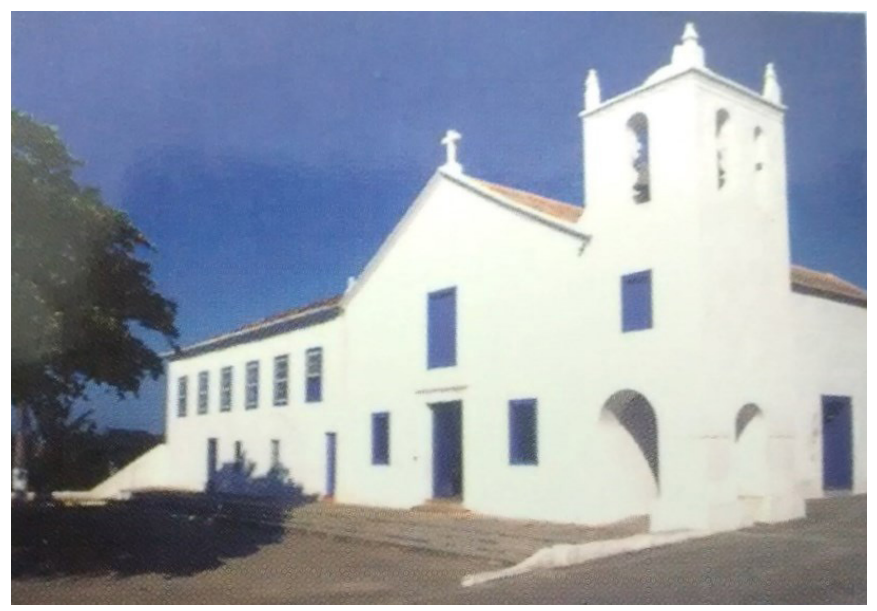

Fonte: Abreu, 1999, p. 9.
Uma das preocupações foi de restabelecer a fachada tal qual se acredita que era no período colonial, como vemos no resultado final da restauração.

Essa obra se apresenta de modo mais amplo em comparação ao livro anterior dedicado à Igreja dos Reis Magos, definindo o que é conservação e restauração: enquanto na primeira se faz somente reparos pontuais, a segunda é ligada a uma redescoberta do monumento, uma reconstrução de sua memória através dos vestígios deixados, uma reconstituição. A obra também expõe o histórico da atuação dos jesuítas no Espírito Santo e evidência os detalhes da restauração, da arquitetura do edificio, assim como as pesquisas e escavações arqueológicas realizadas no local. Dessa forma, também vemos ressaltados os rastros que o monumento deixou para que assim possa ser observada a importância histórica da atuação jesuítica no Espírito Santo.

Ademais, o livro afirma que o conjunto é uma memória viva, e prossegue traçando um histórico da atuação dos jesuítas na região e dos diversos usos que o monumento teve no passar dos anos. Depois, o livro se encaminha para os reparos efetuados e as descobertas arqueológicas encontradas. Dessa forma, toda a obra é voltada para afirmar que uma preservação efetiva de um patrimônio material é feita pela redescoberta e pelo o empenho de que se prevaleça diante da ação do tempo.

\section{CONSIDERAÇÕEs FINAIS}

Para um historiador pesquisar sobre um patrimônio material, é necessário que investigue os traços deixados, tanto materiais como da memória preservada, aliado ao histórico a ele associado.

A leitura dos dois livros produzidos para edifícios distintos e em períodos diferentes revela formas diversas de pensar o patrimônio material e como preservá-lo por meio da conservação e restauração: enquanto o primeiro privilegia sua importância estética, o segundo destaca o histórico que há no monumento.

Dessa forma, uma conservação do estético ou a partir de seu histórico são formas diferentes de compreender a lei acerca da salvaguarda de patrimônio cultural inscrito no livro do tombo do Iphan. 


\section{REFERÊNCIAS}

ABREU, C. (Org.). Anchieta: a restauração de um santuário. Rio de Janeiro: Iphan, 1998.

ALMEIDA, M. R. G. Catequese, aldeamento e missionação. In: GOUVÊA, M. F. FRAGOSO, J. O Brasil Colonial: 1443-1580. Rio de Janeiro: Civilização brasileira, 2014. v. 1. p. 435-478.

BRASIL. Casa Civil. Decreto-Lei no 25, de 30 de novembro de 1937. Organiza a proteção do patrimônio histórico e artístico nacional. Diário Oficial da União, Poder Executivo, Rio de Janeiro, 6 dez. 1937.

BURKE, P. Testemunha ocular. Bauru: EDUSC, 2004.

CAVALCANTI, L. Moderno e brasileiro: a história de uma nova linguagem na arquitetura (1930-1960). Rio de Janeiro: Zahar, 2006.

COSTA, L. A arquitetura dos jesuítas no Brasil. Revista do Patrimônio Histórico e Artístico Nacional, Rio de Janeiro, n. 5, p. 3-103, 1941.

FUnARI, P. P.; PELEGRINI, S. C. A. Patrimônio histórico e cultural. Rio de Janeiro: Jorge Zahar, 2009.
GINZBURG, C. Mitos, emblemas e sinais: morfologia e história. São Paulo: Companhia das Letras, 1989.

KESSEL, G. Estilo, discurso, poder: arquitetura neocolonial no Brasil. Revista Brasileira da História Social, Campinas, n. 6, p. 65-94, 1999.

LANARI, R. A. O. A cidade que não morreu: modernidade e tradição no Guia de Ouro Preto, de Manuel Bandeira. Revista Científica das Áreas de Humanidades do Gentro Universitário de Belo Horizonte, Belo Horizonte, v. 6, n. 1, p. 1-20, 2013.

LE GOFF, J. Documento/Monumento. In: ROMANO, R. (Dir.). Enciclopédia Einaudi: memória/história. Porto: Imprensa Nacional; Casa da Moeda, 1984. v.1.

LEITE, S. Artes e ofícios dos jesuítas no Brasil (1549-1760). Lisboa: Brotéria, 1953.

MOTTA, A.; RAMOS, O. Caderno de restauração 1: Retábulo e elementos em cantaria da Igreja do convento dos Reis Magos Nova Almeida - Espírito Santo. Salvador: Restauro, 1990.

PELEGRINI, S. C. A. Patrimônio Cultural: Consciência e preservação. São Paulo: Brasiliense, 2009. 